\title{
Выявление ключевых факторов создания стоимости компании при оценке интернет-фирм доходным подходом
}

\author{
Артемов С.В. ${ }^{7}$, Березинец И.В. ${ }^{8}$
}

Данная работа посвящена проблеме выделения ключевых факторов стоимости в прочессе оценки компаний, осуществляющих свою деятельность в Интернете. Вопросы, оставшиеся у экспертов и аналитиков фондового рынка после кризиса 2000 года, относительно оценки этих весьма специфических объектов, так и остаются открытыми на сегодняшний день. Данная работа ставит своей целью описать особенности интернеткомпаний как объектов оченки, предложить их классификацию и наконеи продемонстрировать, что российские интернет-компании даже в условиях отсутствия рыночных котировок могут быть адекватно оценены традиционным методом дисконтирования денежных потоков за счет выделения ключевых факторов создания иенности, набор которых различен для различных типов интернет-компаний в рамках предлагаемой авторами классификачии. Применение классического оченочного инструментария для нахождения стоимости интернет-компаний предполагает не только знание традиционных формул и алгоритмов в рамках финансового менеджмента, но $u$ понимание технологии бизнеса оцениваемой компании. Классификация интернет-компании относительно механизмов получения доходов, прогнозирование выручки на основе фундаментальных факторов роста, характерных именно для данного объекта оценки, позволяют успешно применять классические методы оченивания.

JEL: G11, G15.

Ключевые слова: оценка стоимости, ключевые факторы стоимости, финансовые пузыри

\section{Введение}

Эпоха «бума dot.com» и последовавший за ней кризис фондовых бирж уже давно в прошлом, однако интернет-компании все чаще оказываются в центре внимания финансовой прессы, привлекая миллиарды долларов в рамках IPO и поглощая друг друга с рекордными премиями. Google покупает YouTube в 2006 году за 1,6 млрд долл., Microsoft приобретает долю в крупнейшей социальной сети Facebook в 2008 году, оценивая компанию по итогам этой сделки в 15,6 млрд долл. Сегодня мы можем с уверенностью говорить о второй волне всемирного интереса к интернет-компаниям. И это объяснимо. Согласно данным WorldStats, в период с 2000-го по 2007 год количество пользователей Всемирной сети выросло с 360 млн до 1,3 млрд человек (число пользователей в Азии увеличилось на $346 \%$, в Латинской Америке - на 548\%). Кроме того, широкое распространение получили множественные инновационные технологии в телекоммуникациях (Wi-Fi, Wi-Max, 3G) и в создании и управлении веб-страницами. Последняя группа технологий была объединена под термином «Web 2.0», который используется для обозначения методов создания нового типа интернетстраниц, более интерактивных, предоставляющих множество новых возможностей и сервисов для пользователей, к примеру воспроизведение аудио- и видеофайлов в реальном времени.

\footnotetext{
${ }^{7}$ Выпускник Высшей школы менеджмента (Санкт-Петербург). Специальность - «менеджмент организации». Специализация - «финансовый менеджмент».

8 К.ф.-м.н., доцент кафедры финансов и учета Высшей школы менеджмента (Санкт-Петербург). Член Европейской бухгалтерской ассоциации.

Выпуск \#3(7), 2008 구의 Элекронный журнал Корпоративные Финансы, 2008
} 
За последние несколько лет было опубликовано достаточно большое количество исследований, посвященных бизнесу и компаниям в Интернете, однако значимые исследования в рамках проблематики оценки стоимости бизнеса в этом направлении практически отсутствуют и ограничиваются несколькими статьями в специализированных журналах и одной монографией. Монография - это «Internet Valuation: the Way Ahead» [Briginshow, 2002], автор которой много лет проработал инвестиционным аналитиком и консультантом в сфере оценки стоимости интернет-компаний. Данная работа была опубликована уже после биржевого кризиса 2000 года и поэтому содержит не только описания преимуществ данного типа компаний, но и выделяет недостатки и ограничения бизнес-моделей в Сети, в чем заключается ее неоспоримая ценность. Среди статей, посвященных данной теме, стоит выделить работу Шварца и Муна [Schwartz, Moon, 2000], в которой используется инструментарий реальных опционов для нахождения фундаментальной стоимости крупных интернет-фирм. При этом статья, вышедшая до марта 2000 года, то есть до кризиса на NASDAQ, полностью оправдывает существовавшую на тот момент высокую капитализацию интернет-компаний. Вторая редакция данной статьи, вышедшая после падения котировок, содержит уже совершенно другие оценки. Также в период с 1998-го по 2000 год сразу в нескольких американских и европейских изданиях по финансам различными авторами были предприняты попытки провести статистические исследования по нахождению взаимосвязей между рыночной капитализацией интернеткомпаний и другими показателями деятельности, такими как выручка, прибыль, количество уникальных пользователей, количество просмотров страниц, рейтинги популярности ресурса в сети и др. Среди такого рода публикаций можно назвать работы Пенмана [Pennman, 2001], Токича [Tokic, 2005], Трумэна, Вонга и Жанга [Trueman, Wong, Zhang, 2000, 2001]. Все эти исследования приводят к противоречивым результатам, и единственный вывод, который можно сделать, - это то, что для разных интернет-фирм на разных временных промежутках стоимость компании находилась в тесной взаимосвязи с совершенно различными показателями деятельности. Среди русскоязычных изданий по финансам не было опубликовано ни одной работы, посвященной проблемам оценки стоимости компаний данной отрасли. И это при том, что российский сегмент Всемирной сети на сегодняшний день является одним из наиболее динамично развивающихся в мире. Российские интернеткомпании постоянно заявляют о своих намерениях привлекать значительные объемы финансирования на публичных рынках капитала [11, с. 23]. В этой ситуации менеджеры и инвесторы должны адекватно представлять методики оценивания компаний и избегать ошибок, которые привели к существенной переоценке данных активов в конце XX века.

\section{Основные предпосылки оценки стоимости интернет-компаний}

Основным заблуждением, послужившим причиной кризиса на NASDAQ, стало предположение о том, что интернет-компании в силу своих специфических особенностей не должны оцениваться традиционными подходами и требуют совершенно иных оценочных моделей. Именно отход от фундаментального принципа оценки на основе будущих прибылей и денежных потоков и использование альтернативных моделей, в том числе реальных опционов и моделей на основе измерения посещаемости и других нефинансовых показателей, позволили рыночным котировкам оторваться от фундаментальных значений стоимости и, превосходя здравый смысл, устремиться вверх. Проблема на самом деле заключается не в слабости традиционных моделей оценки, а в исключительном многообразии интернет-компаний. Именно поэтому правильная классификация объектов оценки, основанная на различиях в механизмах извлечения дохода, должна служить отправной точкой в процессе нахождения фундаментальной стоимости подобных фирм.

На 2008 год были запланированы IPO крупнейших российских интернет-ресурсов Mail.ru и «Яндекса»; возможная капитализация каждой из компаний по итогам размещения оценивается от 3 до 5 млрд долл. Текущая кризисная ситуация на фондовых рынках, скорее 
всего, заставит менеджеров «Яндекса» и Mail.ru отложить вывод компаний на биржу. Тем не менее очевидно, что IPO ведущих интернет-компаний стоит ожидать в ближайшем будущем. Размещение акций этих компаний, безусловно, станет событием для всего интернет-бизнеса в России, так как это наконец предоставит всем остальным его участникам долгожданные стоимостные ориентиры. В преддверии этих событий стоит задаться вопросом о том, какие уроки вынесли участники рынка из прошлого кризиса 2000 года и научились ли с тех пор специалисты правильно оценивать эти компании? Попытки оценивать компании на основе рейтингов популярности, посещаемости и других нефинансовых показателей, предположения о бесконечно высоких темпах роста продаж, постоянстве затрат на поддержание инфраструктуры интернет-сайта и, как следствие, аномально высокий операционный левередж, приводящий к высокому значению рентабельности активов (ROA), - вот те основные предпосылки, на которых строились в конце XX века ошибочные модели оценки интернет-компаний. При этом широкое применение всевозможных мультипликаторов в рамках сравнительного подхода привело к переоцененности всей отрасли. Прежде чем перейти непосредственно к моделям оценки стоимости интернеткомпаний, необходимо сначала более трезво оценить данные предпосылки.

Начинающие интернет-стартапы как в России, так и за рубежом отличаются высокой степенью неопределенности, так как действуют на зарождающихся рынках или рынках, создаваемых собственно самими этими компаниями. Анализ финансовой отчетности российских интернет-компаний показывает, что для ведущих игроков более чем 100\%-ный годовой рост продаж последовательно, в течение нескольких лет, является нормой (см. Приложение 1), в то время как компании, входящие в индекс РТС, за аналогичный период демонстрировали в среднем 49\%-ное увеличение оборота. Однако уже сейчас четко определена тенденция к замедлению этого роста в развитых странах, где доля пользователей Сети составляет на сегодняшний день от 50 до 70\% населения страны. Многие компании могут удваивать продажи, но когда оборот достигает нескольких миллиардов долларов (как у Google или eBay, к примеру), поддерживать прежний рост становится гораздо сложнее. Не стоит забывать и о законах арбитражной теории, согласно которым любая отрасль, в которой наблюдаются показатели роста и прибыльности выше, чем среднерыночные, будет притягивать новых участников до тех пор, пока рост и рентабельность не стабилизируются.

Еще одно заблуждение, которым руководствовались эксперты в сфере информационных технологий и фондовые аналитики в период 1998-2000 годов, заключалось в том, что интернет-сайт может обслуживать бесконечное количество посетителей без существенного возрастания издержек, или обладает существенным операционным левереджем. То есть наблюдается значительный эффект операционного левереджа из-за того, что в структуре затрат компании преобладают постоянные издержки. При этом фирма терпит убытки при небольшом объеме продаж, однако способна достигнуть высокой рентабельности при увеличении оборота. К примеру, сайт интернет-магазина автоматизирует практически все этапы процесса покупки (а иногда и весь цикл покупки, если речь идет о торговле электронными товарами). Сайт предоставляет возможность просмотра и изучения потенциально неограниченного ассортимента товаров (сокращение затрат на торговые площади), выполняет одновременно функции справочной и консультационной службы (сокращение издержек на персонал), позволяет осуществлять платежи (тем самым сокращаются затраты на кассовое обслуживание). Таким образом, торговля в Интернете сокращает затраты и одновременно изменяет их структуру: большая часть становится постоянной, тем самым реализуется эффект операционного левереджа. Учитывая потенциально неограниченные рынки и благодаря способности осуществлять продажи пользователям по всему миру, эффект «операционного рычага» представлялся колоссальным. На самом деле такое предположение является ошибочным. В реальности расходы на содержание сайта, его модернизацию и добавление новых сервисов в ответ на аналогичные действия конкурентов никогда не бывают постоянными. Напротив, нередко вложения в развитие и «раскрутку» (всевозможные рекламные акции в Сети для выведения 
сайта на верхние позиции в рейтингах и увеличения его посещаемости) требуют привлечения дополнительного финансирования, так как внутренних ресурсов недостаточно для осуществления этих планов (особенно на ранних стадиях жизненного цикла компании).

Некоторые эксперты также приписывали интернет-компаниям возможность достигать более высоких показателей рентабельности активов по сравнению с компаниями других отраслей [14, p. 55-65]. В частности, сравнивались показатели интернет-магазинов и магазинов розничных сетей. К примеру, увеличение товарного ассортимента Barnes \& Nobles (крупнейшей сети по торговле книгами в США) в два раза потребовало бы аналогичного расширения торговых площадей и соответственно увеличения инвестиций в недвижимость. В то время как его «виртуальному» конкуренту - Amazon.com - достаточно было лишь, как казалось, создать несколько новых разделов в рамках своего сайта. Это, в свою очередь, предполагало, что затраты на расширение торговли Amazon.com ниже.

Однако покупатель в Сети имеет возможность легко сравнить цены среди нескольких десятков предложений. В таких условиях торговые наценки интернет-магазинов стремятся к минимуму. Иными словами, товары в Интернете могут быть действительно дешевле, чем в обычных магазинах (более низкая рентабельность продаж), однако вложения в торговые площади и другие затраты не требуются (более высокая оборачиваемость активов). Результирующий фактор - рентабельность активов у интернет-компаний и традиционных розничных сетей остается на одном уровне.

Рассмотрим данное предположение с точки зрения декомпозиции показателя рентабельности активов:

$$
R O A=\frac{E B I T}{T A}=\frac{\text { Sales }}{T A} \times \frac{E B I T}{\text { Sales }}=\text { assets turnover } \times \text { sales } m \text { arg in }
$$

где ROA - рентабельность активов;

EBIT - операционная прибыль компании;

ТА - величина активов;

Sales - выручка компании;

assets turnover - коэффициент оборачиваемости активов;

sales margin - рентабельность продаж.

Таким образом, даже если первый сомножитель $\frac{\text { Sales }}{T A}-$ оборачиваемость активов - у интернет-магазина выше, чем у других ретейлеров (мы уже рассмотрели, почему это не всегда выполняется), то величина второго сомножителя у интернет-магазинов ниже, что приводит к нивелированию преимущества, порождаемого более низкими капиталовложениями.

Большинство исследований, посвященных проблемам оценки стоимости интернеткомпаний, отмечают важность таких нефинансовых показателей, как количество уникальных пользователей (unique users) и количество просмотров страниц (page views) для процесса нахождения фундаментальной стоимости данных фирм. На основе первого показателя рассчитывается наиболее популярный мультипликатор, используемый для оценки стоимости интернет-компаний: средняя выручка на одного пользователя (более распространено обозначение APU - average per user). Однако эксперты, определяющие фундаментальную стоимость компании на основе этих показателей или сравнивающие рейтинги популярности различных интернет-проектов, упускают ряд важных факторов. Высокая посещаемость сайта не всегда означает высокую покупательную активность его пользователей. Если в основе бизнес-модели оцениваемой компании лежат доходы от продажи рекламных площадей, то высокая посещаемость, безусловно, означает большую выручку для этого рекламодателя. Однако для интернет-магазинов или компаний, предоставляющих платный доступ к информации, посещаемость далеко не всегда имеет высокий положительный коэффициент корреляции с доходами компании. Поэтому для выявления значения посещаемости в 
процессе создания стоимости компании необходимо четко определить бизнес-модель в терминах ключевых драйверов создания ценности. При этом посещаемость может оказаться далеко не на первом месте. Эксперты McKinsey в рамках своей модели оценки эффективности функционирования интернет-компании McKinsey ePerformance задействуют три группы факторов:

- факторы привлечения посетителей (посещаемость сайта и затраты на привлечение новых пользователей);

- покупательная активность (доля посетителей, совершающих покупки/ делающих заказы; темпы роста доходов от продаж основных продуктов, время пребывания посетителя на сайте);

- постоянство аудитории (доля покупок/ заказов постоянных клиентов в доходе от продаж, отношение количества постоянных клиентов к общему числу посетителей/ покупателей компании, коэффициент ухода постоянных клиентов, темпы прироста постоянных клиентов).

Из вышеприведенного списка факторов видно, что посещаемость - далеко не единственный показатель, значимый для создания стоимости. Однако выявление драйверов стоимости - это только один шаг на пути к определению фундаментальной ценности интернет-компании. В первую очередь необходимо определить, при помощи каких подходов будет оцениваться такая компания. Рассмотрим особенности использования классических подходов (затратного, сравнительного и доходного) при оценке интернет-фирм.

Материальные активы, как правило, составляют небольшую часть от оборота и менее важны для интернет-компании, чем для фирм в других отраслях. Для многих интернеткомпаний материальные активы могут быть лишь товары на складе и компьютерное оборудование. Однако крупные интернет-магазины предпочитают самостоятельно осуществлять весь цикл логистических операций. Такой практики придерживаются как крупнейший американский интернет-ретейлер Amazon.com, так и российский «Озон»: обе компании активно инвестируют в последние годы в собственные складские площади. Более мелкие интернет-магазины могут позволить себе использование почтовой службы или сторонних транспортных компаний для доставки товаров. Преобладание у интернеткомпаний нематериальных активов существенно затрудняет применение затратного подхода для их оценки. Определить, даже приблизительно, какой объем инвестиций потребуется для создания портала, аналогичного, скажем, «Яндексу», практически невозможно.

Говоря о структуре активов, следует остановиться на еще одной важной особенности. Она заключается в низкой доле амортизации в структуре затрат интернет-фирмы. Это приводит к тому, что, в отличие от традиционных компаний, интернет-компании не способны амортизировать свои ключевые активы. Затраты на рекламу не капитализируются и сразу списываются в отчете о прибылях и убытках. Чем больше фирма вкладывает в рекламу сайта, тем ниже будет ее прибыль за текущий отчетный период. Подобная особенность интернет-компаний наиболее отчетливо проявилась в период 1995-2000 годов, когда многие исследователи отметили положительный коэффициент корреляции между текущими убытками и капитализацией интернет-компаний, что стало поводом для всеобщей иронии. На самом же деле данная взаимозависимость абсолютно обоснованна, так как интернет-фирма на ранней стадии развития должна стремиться как можно скорее захватить внимание пользователей, и серьезные инвестиции в рекламу именно на ранних стадиях существования проекта могут стать определяющими в конкурентной борьбе (если бизнесмодель окажется удачной, разумеется).

Сравнительный подход является наиболее простым способом оценить практически любую компанию и служит для проведения экспресс-оценок или для дополнения и проверки результатов, полученных в результате доходного подхода. Однако в отношении интернеткомпаний в России стоит учитывать ряд специфических недостатков сравнительного подхода: 
- Страновой фактор. Более корректным является сравнение компаний, работающих в одной стране. Там, где более высокие страновые риски, денежные потоки компании должны дисконтироваться по более высоким ставкам для отражения дополнительной неопределенности. Причины этого не только в политическом риске, но и в стабильности экономики, устойчивости покупательной способности населения, курса национальной валюты и т.д. Это одна из причин, по которым оценка российских интернет-компаний на основе мультипликаторов Google или еВау никогда не будет достоверной.

- Отраслевой фактор. Между отраслями существуют значительные различия, влияющие на оценку бизнеса. Связано это с различными темпами роста отраслей, уровнем риска и доходности, капиталоемкостью, различиях в государственном регулировании отраслей, структуре конкуренции и многих других факторах. Однако Интернет предоставляет пользователям не только огромное разнообразие товаров, но также множество видов услуг и сервисов. Именно поэтому Всемирную сеть нельзя рассматривать как единую отрасль. Вследствие этого оценка компании Amazon.com в соответствии с мультипликаторами компаний Google и eBay, строго говоря, не является корректной. Наилучшими аналогами для Amazon.com являются крупнейшие розничные сети США, такие как Barnes \& Noble (крупнейший книжный ретейлер), Wal-Mart, Borders Group, Target.

- Фактор размера. Крупные компании и лидеры отрасли более стабильны, предсказуемы и соответственно менее рискованны, чем мелкие компании. Поэтому определение стоимости локального российского сайта на основе мультипликаторов таких компаний, как Amazon.com или Google, некорректно.

- Мультипликаторы основываются на прошлых или текущих данных и тем самым нарушают важный в оценочной практике принцип - оцениваются будущие выгоды владения активом, а не его прошлые заслуги [15]. Для большинства интернеткомпаний основную часть стоимости могут составлять именно ожидания будущих доходов.

Таким образом, были перечислены основные недостатки использования затратного и сравнительного подходов к оценке стоимости интернет-компаний. Доминирующую роль в оценке интернет-компаний следует отдать доходному подходу, так как только оценка на основе дисконтирования будущих прибылей и денежных потоков приводит к наиболее адекватной величине стоимости данных компаний, несмотря на их специфические особенности.

Следует отметить, что одной из наиболее существенных особенностей интернеткомпаний является отсутствие положительной прибыли и положительного денежного потока на момент оценки. Однако это не должно вводить в заблуждение при оценивании стоимости компании в результате доходного подхода. Инвесторы вкладывают деньги в интернет-компании по той же самой причине, по какой они инвестируют в любые другие компании: они хотят участвовать в будущих прибылях (доходах) бизнеса [14, p. 23]. Отсутствие положительного денежного потока не означает невозможность применения традиционных подходов на основе дисконтированных денежных потоков или остаточных прибылей фирмы. Однако отрицательный денежный поток в сочетании с отсутствием финансовой истории ставит вопрос об адекватных методиках прогнозирования будущих доходов компании. Когда компания на протяжении всего периода деятельности не демонстрировала положительной прибыли и денежного потока, ключевым вопросом становится методика прогнозирования будущих доходов. Согласно У. Баффету: «Стоимость разрушается, а не создается любым бизнесом, который теряет деньги в течение своей жизни» [15].

Ожидания будущего роста доходов (в первую очередь выручки от продаж) составляют большую часть стоимости многих начинающих интернет-компаний. В условиях отрицательной прибыли и денежного потока на момент оценки именно прогнозирование

Выпуск \#3(7), 2008 () Электронный журнал Корпоративные Финансы, 2008 
будущего роста становится одним из критических условий, необходимых для нахождения справедливой стоимости фирмы.

\section{Прогнозирование выручки за счет анализа внутренних факторов развития бизнеса}

Большинство традиционных методов прогнозирования выручки основывается на выведение средних темпов роста продаж на основе данных финансовой отчетности за прошлые периоды. Затем результаты вычислений корректируются, для того чтобы учесть перспективы развития отрасли, осуществленные или планируемые инвестиции в расширение деятельности компании, прогнозы менеджмента и другие факторы. Однако подобный подход не может быть применен в условиях отсутствия длительной финансовой истории интернеткомпаний. Если метод экстраполяции неприменим, то остаются более сложные, но и более надежные методы, основанные на выделении и прогнозировании фундаментальных факторов роста компании. При прогнозировании фундаментальных факторов следует выделить два независимых метода:

1. Прогнозирование выручки на основе внешних факторов роста (доли рынка).

2. Прогнозирование выручки на основе внутренних факторов роста.

Прогнозирование выручки через определение будущей доли рынка является весьма трудной задачей, если речь идет о таком динамичном рынке, как Интернет, где инновационные технологии, способные поколебать позиции даже самых сильных игроков, регулярно разрабатываются и внедряются новыми участниками.

Следовательно, остается только второй путь, то есть выявление и прогнозирование факторов роста, специфичных именно для данного конкретного объекта оценки. Иными словами, тем, кто преследует цель оценки стоимости интернет-компании, необходимо проанализировать технологию бизнеса и механизмы извлечения прибыли.

Авторы считают, что для того чтобы решить указанную задачу анализа, на первом этапе оценки необходимо произвести классификацию компаний, согласно которой все потенциальные объекты оценки в Интернете в зависимости от реализуемой бизнес-модели можно разделить на три большие группы:

1. Интернет-магазины.

2. Порталы.

3. Поставщики содержимого.

Интернет-магазины - это компании, основным видом деятельности которых является продажа товаров (физических или электронных) посредством Интернета. Необходимо проводить различие между электронной торговлей физическими товарами и электронной торговлей интеллектуальными и информационными продуктами, которые могут быть доставлены непосредственно через Интернет (программное обеспечение, информация, изображения, мультимедиа, тексты и т.д.). Потенциальными источниками конкурентных преимуществ интернет-магазинов являются:

- Доступ к широкой аудитории.

- Более высокая рентабельность активов за счет меньших вложений в торговые площади.

- Более высокая рентабельность продаж из-за высокого эффекта операционного левереджа.

Однако бизнес-модели интернет-магазинов характеризуются следующими ограничениями:

- Более острая конкуренция из-за незначительных первоначальных инвестиций приводит к уменьшению торговых наценок; и, следовательно, снижается рентабельность продаж. Интернет по своей структуре близок к совершенной конкуренции, а чем эффективнее рынок, тем более низкой нормы рентабельности следует ожидать. 
- Тот факт, что компании торгуют онлайн, одновременно является ограничением на ассортимент предлагаемых товаров.

- Потребитель не имеет возможности получить товар непосредственно после оплаты (если речь идет о торговле физическими товарами). Поэтому, по данным Jupiter Communication, 65\% покупателей используют Интернет, чтобы изучить приобретаемый товар, однако затем совершают покупку в обычном магазине.

Порталы - сайты, объединяющие интернет-ресурсы и предоставляющие удобный доступ к другим сайтам, а также аккумулирующие большие массивы информации, упорядоченные по определенным признакам. К этому типу относятся и поисковые системы. Порталы, в отличие от интернет-магазинов, не продают никаких конкретных физических или электронных товаров и являются бесплатными для пользователей. Несмотря на бесплатный доступ, подобный интернет-ресурс, безусловно, является коммерческим проектом. Доходы в случае реализации данной модели поступают в основном из двух источников:

- Доходы от размещения информации. Компании, занятые в отрасли или обслуживающие рыночный сегмент, на который ориентирован портал, заинтересованы в размещении своей информации на страницах этого интернетpeсурса. Чем больше компаний, действующих в том или ином рыночном сегменте, представлено на портале, тем сильнее мотивация в подобном присутствии.

- Доход от рекламы. Благодаря своей сфокусированности на каком-либо отраслевом или потребительском сегменте портал предлагает рекламодателям доступ к заранее отобранной аудитории, заинтересованной в приобретении именно тех товаров или услуг, с которыми связана тематика портала. Крупнейшим интернет-порталом в мире является Google, в России это Mail.ru и «Яндекс». Бизнес-модели этих компаний во многом схожи - около 95\% выручки составляют доходы от контекстной рекламы. То есть клиенты порталов оплачивают свое присутствие на первых строках результатов по определенному запросу пользователя (к примеру, страховая группа Allianz будет занимать насколько первых строк в результатах поиска по ключевым словам «КАСКО» и «Страхование ответственности»). При этом клиент платит не фиксированную плату за период, а оплачивает каждый переход пользователя по ссылке в результатах поиска. Рост количества пользователей ведет к росту доходов от контекстной рекламы, которые составляют до $80 \%$ денежных поступлений портала. Прогнозирование количества пользователей является гораздо более легкой задачей, чем прямое прогнозирование выручки, и данные результаты позволяют строить объективные и обоснованные прогнозы будущей деятельности интернет-фирмы, которые становятся основой более надежных моделей оценки фундаментальной стоимости данных объектов.

Поставщики содержимого и виртуальные сообщества (content providers/ community firms) - сайты, предоставляющие определенную информацию на платной основе и сайты интернет-сообществ (в том числе так называемых социальных сетей). В первом случае сайт является источником большого количества информации (содержимого, content) и продает доступ к ней заинтересованным пользователям. Во втором случае речь идет о наиболее перспективном и наиболее обсуждаемом на сегодняшний день сегменте Интернета, то есть о социальных сетях. Сети могут быть как открытыми для пользователей, так и закрытыми (в том числе платными, хотя в этом случае членство, как правило, можно получить только при наличии рекомендаций от действующих участников сети). Facebook, основанный в 2004 году, сейчас насчитывает более 50 млн пользователей, компания заявляет о целях по достижению 200-300 млн участников и оценивается, по итогам недавней сделки с Microsoft, в 15,6 млрд долл. LinkedIn - еще более молодая компания, хотя она и обладает гораздо более скромным количеством пользователей, но является на 100\% состоявшимся коммерческим проектом, объединяя успешных людей и знаменитостей по всему миру, она получает доход от абонентской платы. Самые популярные аналоги в России - социальные сети odnoklassnkiki.ru и vkontakte.ru — в 2008 году вышли на первые места по посещаемости 
среди российских сайтов. Наиболее остро обсуждаемый вопрос на сегодняшний день коммерческая состоятельность данных проектов. Существует два апробированных социальными сетями на практике способа получения прибыли от накопленной аудитории:

- Показ рекламы. Данный способ получения дохода в целом аналогичен тому, который используют порталы. Однако есть и различия. Социальные сети обладают существенными возможностями по индивидуализации показываемой рекламы вплоть до ее адаптации под интересы и предпочтения каждого конкретного пользователя.

- Платные сервисы. Внедрение платных сервисов может существенно уменьшить аудиторию социальных сетей, так как пользователи Интернета высокомобильны. Последствия внедрения платных сервисов могут оказывать негативное влияние на стоимость социальной сети, так как ее ценность для потребителя в первую очередь определяется числом пользователей, то есть числом полезных связей, которые она может предоставить.

После того как будет определен тип бизнес-модели оцениваемой компании, можно переходить к выявлению внутренних фундаментальных факторов роста оцениваемого бизнеса, что, в свою очередь, позволит перейти к прогнозированию финансовых показателей.

Так, например, только для одного типа интернет-компаний - порталов - посещаемость является фундаментальным фактором роста, так как она определяет популярность ресурса и цены продажи его рекламных площадей. Для бизнес-модели интернет-магазина набор фундаментальных драйверов роста более широк, и посещаемость здесь не играет рещающей роли. Здесь уже необходимо учитывать долю покупателей в общем числе посетителей сайта (напомним, что 65\% людей, посещающих сайт, просто изучают товар, а покупку совершают в другом месте), количество постоянных клиентов, средний размер заказа, средний срок выполения и доставки заказа и т.д. Поэтому оценить интернет-магазин без данных управленческого учета невозможно. Для поставщика содержимого или социальной сети посещаемость основной страницы компании также не показательна. Важнее тот факт, каково количество зарегистрированных пользователей, какие платные сервисы они приобретают и какова структура и периодичность подобных платежей.

Таким образом, для нахождения фундаментальной стоимости большинства интернеткомпаний необходим анализ внутренних факторов развития бизнеса, что, в свою очередь, потребует использования данных управленческого учета. В то же время порталы, для которых стоимость компании как раз и может оказаться в центре внимания российских инвесторов в ближайшем будущем, можно попытаться оценить на основе информации о посещаемости их страниц.

\section{Пример использования доходного подхода для оценки стоимости компании «Яндекс»}

Перейдем к оценке стоимости компании «Яндекс» доходным подходом. Поскольку «Яндекс» является порталом, то прогнозирование выручки можно осуществить, используя информацию о посещаемости основной страницы (www.yandex.ru). 
Структура доходов компании «Яндекс», 2005-2006 годы

\begin{tabular}{|l|c|c|c|c|}
\hline \multirow{2}{*}{$\begin{array}{l}\text { Направление } \\
\text { деятельности }\end{array}$} & \multicolumn{2}{|c|}{2005 год } & \multicolumn{2}{|c|}{2006 год } \\
\cline { 2 - 5 } & $\begin{array}{c}\text { Выручка, } \\
\text { тыс. руб. }\end{array}$ & $\%$ & $\begin{array}{c}\text { Выручка, } \\
\text { тыс. долл. }\end{array}$ & $\%$ \\
\hline 1. Контекстная реклама & 875000,04 & 78,9 & $\begin{array}{c}1471 \\
860,00\end{array}$ & 81,6 \\
\hline $\begin{array}{l}\text { 2. Медийная (баннерная) } \\
\text { реклама }\end{array}$ & 175222,00 & 15,8 & 239898,75 & 13,3 \\
\hline $\begin{array}{l}\text { 3. Доходы от партнёрских } \\
\text { программ }\end{array}$ & 32150,00 & 2,9 & 37878,75 & 2,1 \\
\hline 4.Реализация технологий & 709,76 & 1,6 & 30663,75 & 1,7 \\
\hline 5. Прочие доходы & 17744,00 & 0,7 & 5411,25 & 0,3 \\
\hline Итого & $\begin{array}{c}1109 \\
000,00\end{array}$ & 100 & $\begin{array}{c}1803 \\
750,00\end{array}$ & 100 \\
\hline
\end{tabular}

Как видно из таблицы 1, основную долю (около 81,6\%) доходов составляют поступления от продажи контекстной рекламы. В этом отношении бизнес-модель крупнейшего российского поискового портала аналогична Google. Как было показано выше, для данного типа компаний наблюдается сильная взаимозависимость показателей посещаемости ресурса и его выручки. Это объясняется тем, что бизнес-модель порталов, в отличие от интернет-магазинов и поставщиков содержимого, подразумевает в первую очередь доход от рекламной деятельности. Для «Яндекса» и Google именно контекстная реклама является основным источником дохода. Контекстная реклама организована по принципу, согласно которому оплата рекламодателем происходит только после перехода пользователя по ссылке, размещенной на портале. Это позволяет сделать вывод о том, что прогноз количества пользователей в будущем может с большой точностью предсказать величину выручки компании. Как уже было не раз отмечено в этой работе, прогнозирование выручки становится ключевым этапом в рамках оценки быстрорастущих интернеткомпаний.

Исследование русскоязычного сегмента Всемирной сети Интернет, проведенное ComScore в апреле 2008 год, объявило «Яндекс» самым посещаемым российским сайтом (с охватом аудитории $62,4 \%)$, а также поисковой системой номер один $(47,4 \%$ поисковых запросов). По посещаемости в 2008 году «Яндекс» впервые обошел Mail.ru, а по доли рынка поисковых услуг сумел превзойти Google (доля последнего составила 31,2\% запросов). Обратимся к статистике посещаемости «Яндекса». 
Табл. 2.

\section{Статистика посещаемости «Яндекса» за период с апреля 2001-го по июль 2007 года. Источник: www.yandex.ru}

\begin{tabular}{|c|c|c|c|c|c|}
\hline Период & $\begin{array}{c}\text { Среднемесячное } \\
\text { число уникальных } \\
\text { пользователей } \\
\text { в день }\end{array}$ & Период & $\begin{array}{c}\text { Среднемесячное } \\
\text { число уникальных } \\
\text { пользователей } \\
\text { в день }\end{array}$ & Период & $\begin{array}{c}\text { Среднемесячное } \\
\text { число } \\
\text { уникальных } \\
\text { пользователей в } \\
\text { день }\end{array}$ \\
\hline апрель 2001 & 602041 & май 2003 & 1794228 & июнь 2005 & 3042172 \\
\hline май 2001 & 626566 & июнь 2003 & 1742804 & июль 2005 & 3031758 \\
\hline июнь 2001 & 659080 & июль 2003 & 1762816 & август 2005 & 3225327 \\
\hline июль 2001 & 703393 & август 2003 & 1783007 & сентябрь 2005 & 3199384 \\
\hline август 2001 & 779143 & сентябрь 2003 & 1812076 & октябрь 2005 & 3462842 \\
\hline сентябрь 2001 & 800775 & октябрь 2003 & 1915425 & ноябрь 2005 & 3486520 \\
\hline октябрь 2001 & 943348 & ноябрь 2003 & 1914535 & декабрь 2005 & 3652671 \\
\hline ноябрь 2001 & 951173 & декабрь 2003 & 1995190 & январь 2006 & 3867119 \\
\hline декабрь 2001 & 1002519 & январь 2004 & 2085448 & февраль 2006 & 3806574 \\
\hline январь 2002 & 1079164 & февраль 2004 & 2079271 & март 2006 & 4270320 \\
\hline февраль 2002 & 1031495 & март 2004 & 2437062 & апрель 2006 & 3985187 \\
\hline март 2002 & 1112254 & апрель 2004 & 2204890 & май 2006 & 4129629 \\
\hline апрель 2002 & 1134069 & май 2004 & 2195213 & июнь 2006 & 4057856 \\
\hline май 2002 & 1164620 & июнь 2004 & 2204634 & июль 2006 & 4165626 \\
\hline июнь 2002 & 1142559 & июль 2004 & 2205937 & август 2006 & 4242226 \\
\hline июль 2002 & 1176151 & август 2004 & 2235237 & сентябрь 2006 & 4414583 \\
\hline август 2002 & 1209552 & сентябрь 2004 & 2363302 & октябрь 2006 & 4969246 \\
\hline сентябрь 2002 & 1255605 & октябрь 2004 & 2542795 & ноябрь 2006 & 5210068 \\
\hline октябрь 2002 & 1404430 & ноябрь 2004 & 2660210 & декабрь 2006 & 5301368 \\
\hline ноябрь 2002 & 1442072 & декабрь 2004 & 2715782 & январь 2007 & 5570720 \\
\hline декабрь 2002 & 1538945 & январь 2005 & 2838393 & февраль 2007 & 5459769 \\
\hline январь 2003 & 1648587 & февраль 2005 & 2873521 & март 2007 & 5879179 \\
\hline февраль 2003 & 1605885 & март 2005 & 3075398 & апрель 2007 & 5906639 \\
\hline март 2003 & 1783883 & апрель 2005 & 3064374 & май 2007 & 5997340 \\
\hline \multirow[t]{2}{*}{ апрель 2003} & \multirow[t]{2}{*}{1771661} & \multirow[t]{2}{*}{ май 2005} & \multirow[t]{2}{*}{3182708} & июнь 2007 & 6282121 \\
\hline & & & & июль 2007 & 6116313 \\
\hline
\end{tabular}

На основе изучения данных о численности уникальных посетителей в качестве модели, отражающей зависимость числа уникальных посетителей «Яндекса» (переменная у) в зависимости от времени была выбрана следующая модель:

$$
y=\beta_{0} e^{\beta_{1} t} \varepsilon .
$$

В уравнении (2) через $\beta_{0}, \beta_{1}$ обозначены неизвестные коэффициенты, подлежащие оцениваю, через $\varepsilon-$ случайная составляющая, через $\mathrm{t}$ - время.

Данная модель была приведена к линеаризованной модели вида:

$$
\ln y=\ln \beta_{0}+\beta_{1} t+\ln \varepsilon
$$

Оценки параметров линеаризованной модели были найдены методом наименьших квадратов. В результате алгебраических преобразований были найдены оценки параметров исходной модели. В итоге было получено следующее уравнение: 


$$
\bar{y}_{t}=757938 e^{0,028 t} \text {. }
$$

Тестирование модели на значимость позволило принять предположение о значимости нелинейной функции регрессии, устанавливающей взаимосвязь между числом уникальных посетителей от времени. На рис. 1 приведен график фактических значений численности уникальных пользователей «Яндекса», а также график оцененной функции.

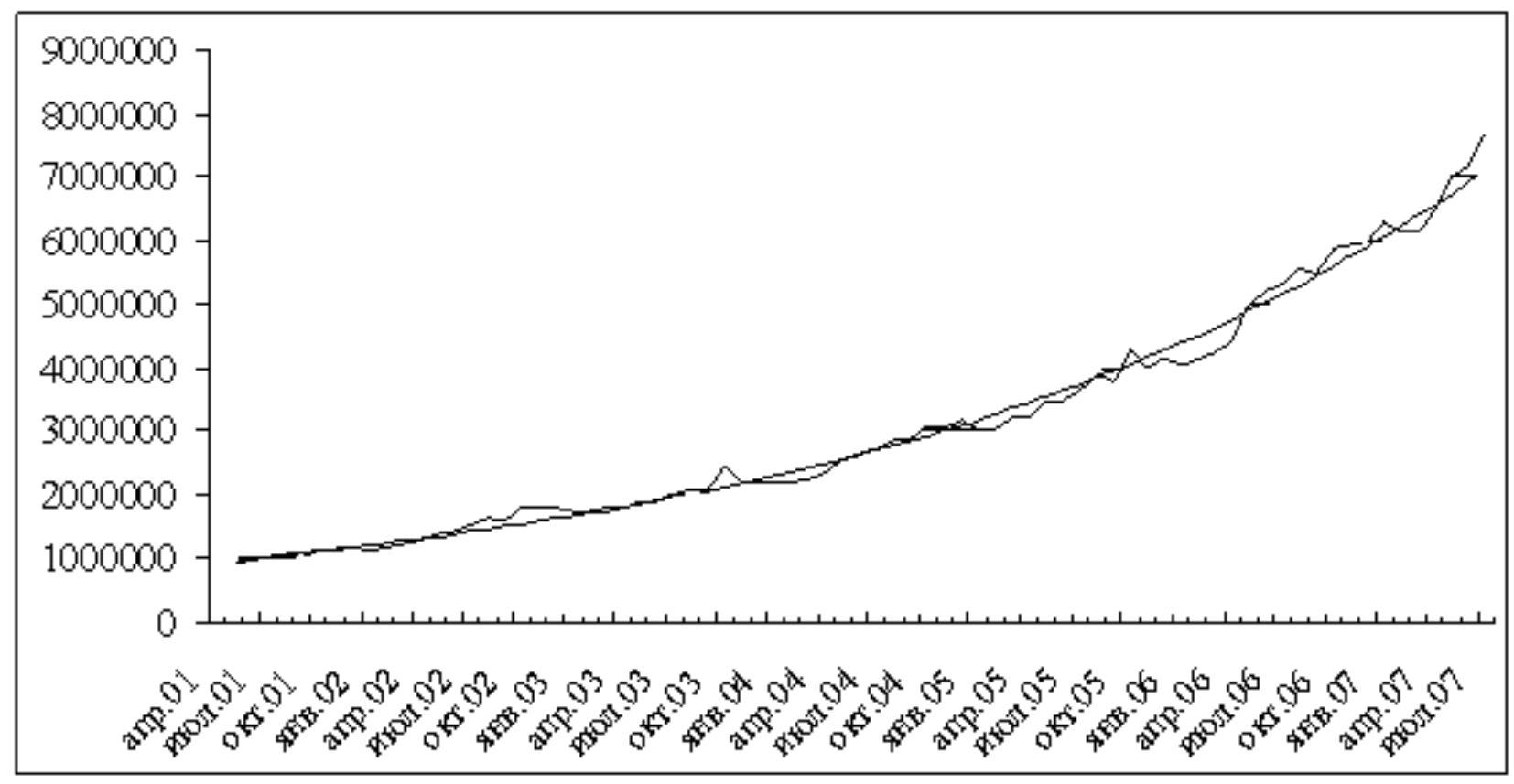

Рис. 1. График изменения числа уникальных пользователей «Яндекса» за период с апреля 2001-го по июль 2007 года и график кривой экспоненциального тренда

При помощи оцененной нелинейной функции (2) был сделан прогноз числа уникальных пользователей на ближайшие 5 лет (с 2007-го по 2012 год включительно). Чтобы перейти от прогноза числа уникальных пользователей к прогнозированию будущей выручки компании, необходимо рассчитать мультипликатор среднего дохода на одного пользователя, APU (равный отношению среднемесячной выручки к среднемесячному количеству уникальных посетителей заглавной страницы www.yandex.ru). На основе величины данного мультипликатора и прогноза численности пользователей «Яндекса» можно сделать предположение относительно величины выручки компании на период с 2008-го по 2012 год. Результаты данных расчетов приведены в таблице 3.

Табл. 3.

Прогноз выручки компании «Яндекс» на основе количества пользователей

\begin{tabular}{|l|l|l|l|l|l|}
\hline Пекиод & 2008 год & 2009 год & 2010 год & 2011 год & 2012 год \\
\hline $\begin{array}{l}\text { Количество уель уникальных } \\
\text { посетителей в месяц, чел. }\end{array}$ & 10264654 & 14367178 & 20109379 & 28146593 & 39396080 \\
\hline $\begin{array}{l}\text { Мультипликатор «Выручка/ } \\
\text { количество пользователей», }\end{array}$ & \multicolumn{5}{|c|}{58,67} \\
\hline
\end{tabular}




\begin{tabular}{|l|l|l|l|l|l|}
\hline месяц & \multicolumn{4}{|l|}{} \\
\hline Выручка, млн руб. & 7226,43 & 10114,66 & 14157,23 & 19815,52 & 27735,29 \\
\hline
\end{tabular}

Итак, прогноз числа пользователей позволил оценить будущие доходы компании. Затраты и стоимость активов, необходимых для поддержания динамичного роста продаж, были спрогнозированы исходя из данных прошлой финансовой отчетности компании. Темп роста выручки в постпрогнозном периоде соответствует прогнозируемому МЭРТ темпу роста ВВП до 2014 года. Результаты прогнозирования операционного денежного потока на период 2008-2012 годов приведены в таблице 4. Таблица 5 содержит прогноз стоимости активов и инвестиционный денежный поток в рамках горизонта планирования.

Табл. 4.

Прогноз операционного денежного потока компании «Яндекс», 2008-2012 годы

\begin{tabular}{|l|r|r|r|r|r|}
\hline Период & 2008 год & 2009 год & \multicolumn{1}{|c|}{2010 год } & \multicolumn{1}{|l|}{2011 год } & 2012 год \\
\hline Показатель & 7226,43 & 10114,66 & 14157,23 & 19815,52 & 27735,29 \\
\hline Темп роста выручки, \% & $34,07 \%$ & $39,97 \%$ & $39,97 \%$ & $39,97 \%$ & $39,97 \%$ \\
\hline $\begin{array}{l}\text { Темп роста в } \\
\text { постпрогнозном периоде, } \%\end{array}$ & \multicolumn{5}{|l|}{} \\
\hline $\begin{array}{l}\text { Себестоимость проданной } \\
\text { продукции, млн руб. }\end{array}$ & 2167,93 & 3034,40 & 4247,17 & 5944,66 & 8320,59 \\
\hline Валовая прибыль, млн руб. & 5058,50 & 7080,26 & 9910,06 & 13870,86 & 19414,70 \\
\hline $\begin{array}{l}\text { Коммерческие расходы, } \\
\text { млн руб. }\end{array}$ & 523,07 & 732,13 & 1024,74 & 1434,30 & 2007,55 \\
\hline $\begin{array}{l}\text { Управленческие расходы, } \\
\text { млн руб. }\end{array}$ & 722,64 & 1011,47 & 1415,72 & 1981,55 & 2773,53 \\
\hline $\begin{array}{l}\text { Операционные расходы, } \\
\text { млн руб. }\end{array}$ & 1245,71 & 1743,59 & 2440,46 & 3415,85 & 4781,08 \\
\hline ЕВІТ, млн руб. & 3812,79 & 5336,67 & 7469,60 & 10455,01 & 14633,62 \\
\hline $\begin{array}{l}\text { Налог на прибыль на ЕВІТ, } \\
\text { млн руб. }\end{array}$ & 915,07 & 1280,80 & 1792,70 & 2509,20 & 3512,07 \\
\hline ОРАТ, млн руб. & 2897,72 & 4055,87 & 5676,90 & 7945,81 & 11121,55 \\
\hline Амортизация, млн руб. & 650,38 & 910,32 & 1274,15 & 1783,40 & 2496,18 \\
\hline $\begin{array}{l}\text { Операционный денежный } \\
\text { поток, млн руб. }\end{array}$ & 3548,10 & 4966,19 & 6951,05 & 9729,21 & 13617,73 \\
\hline
\end{tabular}

Табл. 5.

Прогноз инвестиционного денежного потока компании «Яндекс». 2008-2012 годы

\begin{tabular}{|l|c|c|c|c|c|}
\hline \multicolumn{1}{|c|}{ Период } & 2008 & 2009 & 2010 & 2011 & 2012 \\
Показатель, млн руб. & год & год & год & год & год \\
\hline Стоимость основных средств (на конец & 1734,3 & 2427,5 & 3397,7 & 4755,7 & 6656,4 \\
года) & 4 & 2 & 4 & 3 & 7 \\
\hline Запасы (на конец года) & 0,00 & 0,00 & 0,00 & 0,00 & 0,00 \\
\hline & 1445,2 & 2022,9 & 2831,4 & 3963,1 & 5547,0 \\
Дебиторская задолженность (на конец года) & 9 & 3 & 5 & 0 & 6 \\
\hline Кредиторская задолженность (на конец & 1474,1 & 2063,3 & 2888,0 & 4042,3 & 5658,0 \\
года) & 9 & 9 & 8 & 7 & 0 \\
\hline
\end{tabular}




\begin{tabular}{|l|c|c|c|c|c|}
\hline Инвестированный капитал & $\begin{array}{c}1705,4 \\
4\end{array}$ & $\begin{array}{c}2387,0 \\
6\end{array}$ & $\begin{array}{c}3341,1 \\
1\end{array}$ & $\begin{array}{c}4676,4 \\
6\end{array}$ & $\begin{array}{c}6545,5 \\
3\end{array}$ \\
\hline Инвестиционный денежный поток & 513,01 & 681,62 & 954,05 & $\begin{array}{c}1335,3 \\
6\end{array}$ & $\begin{array}{c}1869,0 \\
6\end{array}$ \\
\hline
\end{tabular}

Прогнозирование свободного денежного потока и итоговый результат оценки приведены в таблице 6 .

Табл. 6.

\section{Расчет итогового результата оценки стоимости собственного капитала компании} «Яндекс» доходным подходом.

\begin{tabular}{|c|c|c|c|c|c|}
\hline Показатель & $\begin{array}{c}2008 \\
\text { год }\end{array}$ & $\begin{array}{c}2009 \\
\text { год }\end{array}$ & $\begin{array}{c}2010 \\
\text { год }\end{array}$ & $\begin{array}{c}2011 \\
\text { год }\end{array}$ & 2012 год \\
\hline Операционный денежный поток, млн руб. & 3548,10 & 4966,19 & 6951,05 & 9729,21 & 13617,73 \\
\hline $\begin{array}{l}\text { Инвестиционный денежный поток, млн } \\
\text { руб. }\end{array}$ & 513,01 & 681,62 & 954,05 & 1335,36 & 1869,06 \\
\hline Свободный денежный поток, млн руб. & 3035,09 & 4284,57 & 5997,00 & 8393,85 & $\begin{array}{c}11 \\
748,66 \\
\end{array}$ \\
\hline Ставка дисконтирования, \% & \multicolumn{5}{|l|}{$16,56 \%$} \\
\hline $\begin{array}{l}\text { Приведенная стоимость } \\
\text { свободного денежного потока, млн руб. }\end{array}$ & \multicolumn{5}{|c|}{19552,41} \\
\hline Продленная стоимость, млн руб. & \multicolumn{5}{|c|}{107747,33} \\
\hline $\begin{array}{l}\text { Приведенная стоимость } \\
\text { продленной стоимости, млн руб. }\end{array}$ & \multicolumn{5}{|c|}{50079,37} \\
\hline $\begin{array}{l}\text { Фундаментальная стоимость активов, млн } \\
\text { руб. }\end{array}$ & \multicolumn{5}{|c|}{69631,78} \\
\hline Бухгалтерская стоимость долга, млн руб. & \multicolumn{5}{|c|}{0,00} \\
\hline $\begin{array}{l}\text { Стоимость собственного капитала } \\
\text { компании, млн. руб. }\end{array}$ & \multicolumn{5}{|c|}{69631,78} \\
\hline
\end{tabular}

Таким образом, по итогам проведенного анализа, фундаментальная стоимость компании «Яндекс» была оценена в 69 631,80 млн руб., что, в соответствии с курсом доллара на момент оценки ${ }^{9}$, составило 2969,40 млн долл. Данный результат согласуется с планами компании - в недавних интервью менеджеры «Яндекса» заявляли о планах по достижении капитализации на уровне 3 млрд долл. [11, с. 23].

Итак, крупнейшая российская поисковая система «Яндекс» была оценена при помощи традиционной модели дисконтированных денежных потоков на инвестированный капитал. Применение данной модели было бы невозможно без предварительного определения типа бизнес-модели оцениваемой компании в рамках предложенной в работе классификации. Только после того как было определено, что компания реализует модель портала, основанную на доходах от контекстной и баннерной рекламы, стало возможным найти адекватный механизм прогнозирования выручки объекта оценки на основе посещаемости заглавной страницы www.yandex.ru. Приведенный выше пример оценки компании «Яндекс» соответствует ранее описанному в работе алгоритму, согласно которому определение типа интернет-компании позволяет выделить доминирующие факторы, влияющие на рост выручки компании и зависящие от реализуемой модели бизнеса. Оценка интернет-компании доходным подходом позволяет не только найти конечную величину стоимости, но и

\footnotetext{
${ }^{9}$ 23,45 руб./ долл. на 15 апреля 2008 года. Источник: www.micex.ru. 
проанализировать бизнес-модель компании с точки зрения ключевых драйверов создания ценности. Это позволяет сравнивать полученные результаты с результатами деятельности американских компаний-аналогов, таких как Google, для выявления потенциальных направлений совершенствования бизнес-процессов. Практическая значимость модели проявляется в первую очередь при оценке фундаментальной стоимости компаний, чьи акции еще не обращаются на фондовой бирже, что делает информацию о справедливой стоимости данных объектов гораздо более ценной для менеджеров и инвесторов.

С точки зрения авторов, именно выявление ключевых факторов создания стоимости должно служить отправной точкой при оценке интернет-компании. Анализ и прогнозирование этих факторов в рамках использования традиционной модели оценки на основе дисконтирования денежных потоков помогает преодалеть трудности, связанные со специфичностью интернет-компаний. Набор фундаментальных факторов роста компании может быть специфичен для каждого отдельного объекта оценки. Однако использование классификации, предложенной в работе, существенно облегчает эту нетривиальную задачу. Это может помочь российским участникам фондового рынка избежать тех заблуждений, на которых основывались оценки интернет-компаний в США в период с 1998-го по 2000 год, что в итоге привело к переоценке отрасли и спровоцировало биржевой кризис в марте 2000 года.

\section{Список литературы}

1. Барроу К. Курс выживания Интернет-компании. М.: Альпина Паблишер, 2001.

2. Ботуз С. П. Методы и модели экспертизы объектов интеллектуальной собственности в сети Internet. М.: СОЛОН-Р, 2002.

3. Волков Д. Л. Показатели результатов деятельности: использование в управлении стоимостью компании // Российский журнал менеджмента. - 2005. - № 3(2). - С. 3-42.

4. Волков Д. Л. Управление стоимостью компании и проблема выбора адекватной модели оценки // Вестник С.-Петербургского ун-та. Сер. Менеджмент. - 2002. - № 4. С. $79-98$.

5. Волков Д. Л. Управление ценностью: показатели и модели оценки // Российский журнал менеджмента. - 2006. - № 3(4). - С. 67-76.

6. Волков Д.Л., Березинец И.В. Управление ценностью: анализ основанных на бухгалтерских показателях моделей оценки // Научные доклады НИИ Менеджмента СПбГУ. - 2006. - № 3. - С. 43-65.

7. Волков Д. Л. Теория ценностно-ориентированного менеджмента. С.-Пб: Издательский дом Санкт-Петербургского государственного университета, 2006.

8. Дамодаран А. Инвестиционная оценка: инструменты и методы оценки любых активов. М.: Альпина Бизнес Букс, 2005.

9. Котлярова А. Оценка бизнеса в условиях Интернет-экономики // Открытые системы, 2000. http://www.osp.ru/ecom/2000/05-06/022.htm.

10. Коупленд Т., Коллин Т., Муррин Д. Стоимость компаний: оценка и управление. М.: Олимп-Бизнес, 2004.

11. Трофимова Е. В. Интернет-бум 2.0 // Smart Mоney. Ведомости. - 2008. - № 18. - С. 23 24.

12. Хартман А., Сифонис Дж. Стратегии успеха в Интернет-экономике. М.: Лори, 2001.

13. Чиркова Е.В. Как оценить бизнес по аналогии. М.: Альпина бизнес букс, 2005.

14. Briginshow, J. Internet Valuation: the Way Ahead. - London: Palgrave. 2002.

15. Baffet W. I told you so, BBC News, 2001. http://news.bbc.co.uk/1/hi/business/1217716.stm

16. Bartov E., Mahanram P., Seethamraju C. Valuation of Internet Stocks - an IPO Perspective, Journal of Accounting Research, No. 40, 2002, p. 26-52.

17. Camp J. Trust and Risk in Internet Commerce. - Massachusetts: Massachusetts Institute of Technology, 2000. 
18. Corr. T. Boom, Burst, Boom: Internet Company Valuations - From Netscape to Google, The Financier, No. 13-14, 2006, p. 66-84.

19. Higson K., Briginshaw J. Valuing Internet Businesses, Business Strategy Review, No. 11, 2000, p. 10-22.

20. Kim M. The ability of earnings to predict Future Operating Cash Flows Has Been Increasing Not Decreasing, Journal of Accounting Research, No. 43, 2005, p. 753-780.

21. Penmann S. Discussion of Back to Basics: Forecasting the Revenues of Internet Firms, Review of Accounting Studies, No. 6, 2001, p. 361-364.

22. Schwartz E., Moon M. Rational Pricing of Internet Companies, Financial Analyst Journal, No. 56, 2000, p. 62-75.

23. Tatnall A. Web Portals: the New Gateways to Internet Information and Services. - Hershey: Idea Group Publishing. 2005.

24. Tokic D. R\&D Advertizing and the Market Value of Internet Firms, Journal of Internet Commerce, No. 1, 2005, p. 23-40.

25. Trueman B, Wong M., Zhang X. The Eyeballs Have It: Searching for the Value of Internet Stocks, Journal of Accounting Research, No. 38, 2000, p. 137-162.

26. Trueman B, Wong M., Zhang X. Back to Basics: Forecasting the Revenues of Internet Firms, Review of Accounting Studies, No. 6, 2001, p. 305-329.

\section{Приложения}

Приложение 1. Темпы роста выручки российских интернет компаний в период с 2002 по 2006 гг.

\begin{tabular}{|l|l|l|l|l|l|l|}
\hline \multirow{2}{*}{ Нериод } & & & & & \\
Название компании & 2002 г. & 2003 г. & 2004 г. & 2005 г. & 2006 г. & Среднее за период \\
\hline «Яндекс» & $116,59 \%$ & $187,52 \%$ & $186,58 \%$ & $195,48 \%$ & $126,31 \%$ & $162,50 \%$ \\
\hline «Рамблер интернет холдинг» & $91,71 \%$ & $122,89 \%$ & $71,29 \%$ & $129,64 \%$ & $77,79 \%$ & $98,66 \%$ \\
\hline «Интернет решения» «Озон») & $277,06 \%$ & $101,35 \%$ & $108,83 \%$ & $1,45 \%$ & $16,74 \%$ & $101,09 \%$ \\
\hline «КМ Онлайн» & $86,56 \%$ & $189,51 \%$ & $131,49 \%$ & $26,96 \%$ & $-36,28 \%$ & $79,65 \%$ \\
\hline «Финнам» & $209,85 \%$ & $175,62 \%$ & $257,07 \%$ & $-44,32 \%$ & $27,61 \%$ & $125,17 \%$ \\
\hline Средний темп роста выручки компаний 2002-2006 гг. & & & $113,41 \%$ \\
\hline
\end{tabular}

Составлено авторами на основе данных финансовой отчетности компаний (источник: база данных «Скрин»). 